\title{
Group-based exercise for people with mild cognitive impairment: a pilot study
}

\author{
JUAN TORTOSA-MARTÍNEZ $\square$, NURIA CAUS-PERTEGAZ, CELESTE MARTÍNEZ-CANALES \\ Faculty of Education, University of Alicante, Spain
}

\begin{abstract}
Tortosa-Martínez J, Caus-Pertegaz N, Martínez-Canales C. Group-based exercise for people with mild cognitive impairment: a pilot study. J. Hum. Sport Exerc. Vol. 8, No.Proc3, pp. S702-S710, 2013.The number of neurodegenerative diseases associated to aging, such as Alzheimer's disease (AD), is rapidly increasing. Mild cognitive impairment $(\mathrm{MCl})$ is diagnosed when a person presents cognitive deficits, usually memory related, but still does not meet criteria for a diagnosis of dementia. It is usually considered a transitional phase between normal aging and dementia. The benefits of exercise for people with mild cognitive impairment are not fully clear and deserve further research. The aim of this pilot study was to analyse the physical benefits of a group-based exercise program for people with mild cognitive impairment. Using a pre-post design, twenty people with $\mathrm{MCl}$ were recruited and divided into an experimental group (10), who followed a three-month exercise program, and a control group (10) who followed routine care. The results of this study show that engaging in a supervised exercise program was effective for improving performance in the Six Minute Walk Test (6MWT), the Timed Get Up and Go Test (TGUP), and the 8-meter walk test, implying gains in cardiovascular capacity, gait and dynamic balance. After the intervention period, the control group not only did not improve in any of the fitness tests, but also showed significant worse performance in the (6MWT) and the Tinetti total score. Thus, a supervised group-based exercise program can represent a feasible and effective strategy for improving physical function in people with $\mathrm{MCl}$. Key words: MILD COGNITIVE IMPAIRMENT, PHYSICAL ACTIVITY, ALZHEIMER'S DISEASE, GAIT, BALANCE.
\end{abstract}

Corresponding author. Faculty of Education, University of Alicante, Campus San Vicente del Raspeig, 03080 Alicante, Spain. E-mail: juan.tortosa@ua.es

Performance Analysis Workshop, 2 - 5 April 2013, Alicante, Spain

JOURNAL OF HUMAN SPORT \& EXERCISE ISSN 1988-5202

(c) Faculty of Education. University of Alicante

doi:10.4100/jhse.2013.8.Proc3.17 


\section{INTRODUCTION}

The population of persons with 65 years or older is increasing exponentially due to a higher life expectancy in industrialized countries. As a consequence, the incidence of neurodegenerative diseases in older people such as Alzheimer's disease (AD) is rapidly increasing, creating serious concern for families, caregivers, professionals and others in public health systems (Haan \& Wallace, 2004). Brookmeyer et al., (2007) estimated that in 2006 there were 26 million cases of AD worldwide. They also estimated that in 2050, this number will increase up to a 100 million cases. $A D$ is the most common sub-type of dementia, and it is characterized by a progressive deterioration of higher cognitive functioning in the areas of memory, problem solving, and thinking. Another characteristic is the inability to carry-out everyday tasks or perform instrumental activities (Rimmer \& Smith, 2009).

Considering the projected number of cases and the social and economic impact of $A D$ it is imperative to design feasible strategies to prevent, delay or treat this disease. This has important implications for healthy populations but even more relevant for those who are at more risk of suffering from it. Mild Cognitive Impairment is considered a clinical condition in which the person experiences memory loss to a greater extent to what it would normally be expected from normal aging, but still does not meet criteria for a diagnosis of dementia (Petersen et al., 1999). There are two types of $\mathrm{MCl}$, amnestic and non-amnestic. A diagnosis of amnestic Mild Cognitive Impairment includes memory loss, and it is usually considered a transitional phase between normal aging and Alzheimer's disease (Petersen et al., 2004).

There is a growing body of evidence showing that regular physical activity has protective effects against $\mathrm{MCl}$, dementia, and AD (Laurin et al., 2001; Abbott et al., 2004; Podewils et al., 2004; Rovio et al., 2005; Karp et al., 2006; Larson et al., 2006; Simons et al., 2006; Taaffe et al., 2008; Geda et al., 2010). There is also increasing evidence of the positive effects of physical activity for people who already have Alzheimer's disease and other dementias (Tappen et al., 2000; Arkin, 2003; Williams \& Tappen, 2007; Christofoletti et al., 2008; Lautenschlager et al., 2008; Amand \& Thomas, 2009; Kemoun et al., 2010; Yagüez et al., 2011). However, the benefits of physical activity for people with Mild Cognitive Impairment are less clear, with only a limited number of scientific studies available in the literature (for a recent meta-analysis, see Gates et al., 2013). There is a need for more research in this field to gain a better understanding of the benefits of exercise for people with $\mathrm{MCl}$, and also to advance in the correct prescription of exercise for this population.

Therefore, the aim of this study was to examine the feasibility and physical benefits of a group-based exercise program for people with $\mathrm{MCl}$. We hypothesized that supervised aerobic group exercise would be a feasible strategy for improving physical fitness in this population.

\section{MATERIAL AND METHODS}

\section{Participants}

Twenty people diagnosed with Mild Cognitive Impairment, according to Petersen et al. (2004) criteria, were recruited from the Neurology Unit of the Hospital de San Vicente by trained neurologists using an intentional non-probabilistic sampling method. The sample was divided into two groups: the experimental group (10) who followed an exercise program, and the control group (10) who continued with routine care. Those who were able and willing to attend to the program were included in the experimental group and the rest were allocated in the control group. General exclusion criteria included non-compliance with testing procedures; physical, cardiovascular or sensorial limitations for doing exercise safely; severe apathy, delirium or agitation. 


\section{Measures}

The six minutes walk test (6MWT)

The six minutes walk test (Enright \& Sherrill, 1998) is a submaximal test measuring one's level of aerobic fitness. The test is known to well reflect the functional exercise level during daily physical activities and it is a suitable test for elderly people (Enright et al., 2003). The test has also been used in populations with dementia (Tappen et al., 2000; Arkin, 2003; Williams \&Tappen, 2007).

Participants were requested to walk as far as possible for 6 minutes, without running or jogging, through a circuit of a rectangular shape marked with cones separated five meters each one for a total of 50 meters each complete lap. Participants were allowed to stop if they needed to during the test. A research assistant timed the walk and recorded the distance travelled by participants to the nearest cone.

\section{Timed Get Up \& Go Test}

This test is aimed to assess agility and dynamic balance and has been used previously in people with mild cognitive impairment (Shumway-Cook et al., 2000). The test requires a subject to stand up from a chair, walk 2.44 meters to a cone, turn, walk back, and sit down. Time taken to complete the test is strongly correlated to level of functional mobility. The participant was requested to: "Sit with your back against the chair. At the command 'go,' stand upright, then walk as fast as possible to the cone in front of you, turn around, return to the chair, and sit down. The stopwatch was started on the word 'go' and stopped when the subject returned to the starting position.

\section{Eight meters walk test}

The 8-meter test is a self-paced walking test (Bennell et al., 2011), which measures functional mobility and gait. The individual walks as fast as possible without assistance 10 meters following a visual reference, and the time is measured for the intermediate 8 meters to avoid that the participant stops too early in the test.

Tinetti balance and gait test

The Tinetti test (Tinetti et al., 1986) has been widely used in the elderly to assess balance and gait, and predict falls (Köpke \& Meyer, 2006). It has also been used in people with Mild Cognitive Impairment (Bermejo et al., 2008). The version published by Rubenstein (1992) was applied in this study. This version assesses balance with 9 items (score out of 16) and gait with 7 items (score out of 12) for a total score out of 28 , where the higher the score, the better the performance and lower the risk of falls.

\section{Procedures}

The study followed the principles outlined in the Declaration of Helsinki of 1975. The protocol was approved by an ethics committee, both in the University of Alicante and the Hospital de San Vicente. All participants gave written informed consent to the protocol and were advised that the refusal of participation in the study would not affect future treatment.

\section{Intervention and testing}

The exercise program was conducted for three months, three sessions per week, lasting for one hour each session. Aerobic exercises were the main component of the program. Some strength, balance and flexibility exercises were also included. Aerobic exercises were performed at approximately 60 to $75 \%$ of the maximum heart rate. The intensity started at as low as $40 \%$ and was progressively built up to the target training zone. All participants were monitored with Polar Heart Rate monitors in order to control the intensity of the exercises and the adaptation to the exercise, as well as to assure that the training goals were 
achieved. All sessions included a warm up, main phase, and a cool down. The program was conducted in group, promoting social interaction.

All fitness tests were performed before and after the exercise program by both the experimental group and the control group, in the sports facilities of the University of Alicante.

\section{Statistical Analysis}

Statistical analysis was performed using the SPSS statistical package version (SPSS 19.0. for Windows). Descriptive baseline characteristics were tabulated as mean $( \pm S D)$ for continuous variables or as percentages for categorical ones (Table 1). Data distribution was checked by the Shapiro-Wilk test and homocedasticity was checked by the Levene test. Bivariate relations among the fitness test variables and age, gender, blood pressure and educational level at baseline were assessed by the Pearson correlation coefficient for continuous variables and the Spearman correlation coefficient for non-normally distributed data. Group differences analysis between the experimental group and the control group at baseline was conducted using unpaired t test for normally distributed variables and the Mann-Whitney U-test for nonnormally distributed variables. The effects of the exercise program on the different fitness tests were assessed using a t test for paired samples. All reported $P$ values are two-sided and the significance level was set at 0.05 .

\section{RESULTS}

Main characteristics of the sample

The final sample was comprised of 20 people with $\mathrm{MCI}$ (10 men and 10 women), with a mean age of 76 years-old. Table 1 shows the main characteristics of the sample considering group differences. There were no significant differences between the experimental group and the control group in regards to age, gender, blood pressure or any of the fitness tests.

Table 1. Baseline characteristics of the study population

\begin{tabular}{llll} 
& Sample & $\begin{array}{l}\text { Experimental } \\
\text { group }\end{array}$ & Controlgroup \\
\hline $\boldsymbol{N}$ & 20 & 10 & 10 \\
Age (years) & $76,25 \pm 7,6$ & $74,10 \pm 8,4$ & $78,40 \pm 6,3$ \\
Gender & & & \\
Women & $50 \%$ & $40 \%$ & $60 \%$ \\
Men & $50 \%$ & $60 \%$ & $40 \%$ \\
Systolic Blood Pressure & $133 \pm 12$ & $131 \pm 12$ & $135 \pm 12$ \\
Dyastolic Blood Pressure & $74 \pm 9$ & $75 \pm 10$ & $73 \pm 9$ \\
\hline
\end{tabular}

Correlations at baseline

Considering both groups at baseline, before the exercise program, age was positively correlated with the 8meter walk test [0.462; $p=0.04]$, and negatively correlated with the 6MWT $[-0.549 ; p=0.012]$, the Tinetti balance [-0.555; $p=0.011]$, and the Tinetti total score [-0.548; $p=0.012]$. Gender presented no correlations at all with any of the fitness tests. The results of the different fitness tests were highly correlated to each 
other, except for the Tinetti balance test that was only correlated to the Timed Get Up and Go test [-0.570; $p=0.009]$ and the Tinetti total score [0.694; $p=0.001]$.

Effects of the exercise program in fitness levels

After the exercise program, the experimental group improved the performance in the 6MWT [t=-3,497; $p=0,008]$, the TGUG test $[t=4,747 ; p=0,001]$, and the 8-meter walk test $[t=2,654 ; p=0,029]$. In contrast, the control group did not improve in any of the fitness tests and showed a worse performance in the 6MWT $[t=2,942 ; p=0,016]$ and the Tinetti total score $[t=3,354 ; p=0,008]$.

Table 2. Pre-post test values for the fitness tests

\begin{tabular}{lllll} 
& PreExp. & Post Exp. & PreControl & Post Control \\
\hline $\begin{array}{l}\text { Six Minute Walk } \\
\text { Test (6MWT) }\end{array}$ & $425,00( \pm 46,2)$ & $468,88( \pm 45,0)^{* *}$ & $374,50( \pm 122,5)$ & $340,00( \pm 123,3)^{*}$ \\
\hline 8 meter walk test & $8,50( \pm 2,3)$ & $5,95( \pm 0,9)^{*}$ & $8,24( \pm 3,7)$ & $8,00( \pm 3,2)$ \\
\hline $\begin{array}{l}\text { Timed Get Up \& Go } \\
\text { test (TGUG) }\end{array}$ & $9,66( \pm 1,7)$ & $7,10( \pm 1,6)^{* * *}$ & $10,21( \pm 5,9)$ & $11,00( \pm 4,5)$ \\
\hline Tinetti Balance & $15,22( \pm 1,3)$ & $14,22(1,5)$ & $13,90( \pm 1,7)$ & $12,70( \pm 2,0)$ \\
\hline Tinetti Gait & $10,33( \pm 1,5)$ & $10,77( \pm 1,4)$ & $11,10( \pm 2,2)$ & $11,30( \pm 2,7)$ \\
\hline Tinetti total score & $25,55( \pm 2,4)$ & $25,00( \pm 2,6)$ & $25,00( \pm 2,9)$ & $24,00( \pm 2,8)^{* *}$ \\
\hline
\end{tabular}

\section{DISCUSSION}

Physical activity, when performed regularly, has several benefits for the physical health of older adults such as cardiovascular, gait, or balance benefits (Taylor et al., 2004). There is also increasing evidence about the protective effect of physical activity against developing $\mathrm{MCl}, \mathrm{AD}$, or any other type of dementia (Laurin et al., 2001; Abbott et al., 2004; Podewils et al., 2005; Rovio et al., 2005; Karp et al., 2006; Larson et al., 2006; Simons et al., 2006; Taaffe et al., 2008; Geda et al., 2010). A few studies have focused on the physical benefits of exercise for people with $\mathrm{MCl}$ (Baker et al., 2010; Uemura et al., 2012). A recent metaanalysis conducted by Gates et al. (2013) showed that cognitive benefits resulting from exercise programs for people with $\mathrm{MCl}$ are modest so far.

The present study focused on a group-based exercise intervention to assess the physical benefits and the feasibility of this type of programs for people with $\mathrm{MCl}$. Our results confirm that exercising in group can be feasible and produces physical benefits for this population. Participants in the experimental group improved their performance in several fitness tests such as the 6MWT, the TGUG, and the 8-meter walk test, while their performance in the Tinetti tests remained unchanged. The control group did not improve in any of the fitness tests, but it did show a significant decrease in the performance of the 6MWT and the Tinetti total score.

At baseline, the mean distance covered in the 6MWT was 425 and 374 for the experimental group and the control group respectively, when expected distances for a group of healthy people of similar age would be over 600 meters (Trooster et al., 1999). Thus, people with Mild Cognitive Impairment have a poorer cardiovascular capacity than healthy people of their same age. 
The increase in the mean distance covered in the 6MWT by the experimental group after completing the exercise intervention was 43 meters. The fact that the control group not only did not increase the distance covered during the test, but also decreased the average distance covered by 34 meters, make the positive results of the intervention group even more relevant. These improvements shown in the 6MWT by the intervention group imply cardiovascular and general physical function benefits (Enright \& Sherrill, 1998).

The TGUG test has been correlated with the risk of falls (Shumway-Cook et al., 2000) and more recently with executive function (McGough et al., 2011). A worse performance on this test represents, thus, a higher risk of falling (Shumway-Cook et al., 2000) and it is also correlated with poorer executive function (McGough et al., 2011). Declining physical function combined with decreased cognitive function has been associated with increased risk of dementia and also disability (Scherder et al., 2007). Thus, the significant improvement in the performance of this test shown by the experimental group in our study may represent an opportunity for delaying the onset of dementia and disability.

The 8-meter walk test measures the speed of gait, which is correlated with physical function as well as cognitive function (Scherder et al., 2007). The speed of gait decreases as an adaptation to aging, in order to reduce the risk of falling (Menz et al., 2003). In people with $\mathrm{MCl}$, this slower gait is more pronounced (Scherder et al., 2007). Furthermore, if the person develops a dementia, it usually has as a consequence a higher deterioration of gait, and as the severity of the dementia progresses gait will also continue to deteriorate (Sheridan \& Hausdorff, 2007). In our sample, the experimental group improved significantly the performance in the 8-meter walk test after the exercise program, which represents an improvement in their physical functionality. An older adult's ability to increase walking speed above a "comfortable" pace may correlate with a potential to adapt to varying environments and task demands (eg, crossing streets; avoiding obstacles) (Steffen et al., 2002). However, we did not measure activities of daily living so we can't be sure about the impact of this improvement in the participants' daily lives.

Balance and gait are highly correlated to risk of falling (Köpke \& Meyer, 2006). Falling is considered a serious public health concern among elderly people due to its frequency, the morbidity often associated, and the cost of the necessary health care after falling (Tinetti et al., 1994). In our study, the Tinetti test was used to assess static balance and gait, having a separate score for each variable and a composite score for both of them. Using the version published by Rubenstein (1992), a total score of less than 18 would correlate with high risk of falling, a total score of between 18 and 23 would represent a moderate risk of falling, while a total score higher than 24 would be considered a low risk of falling. Both groups (experimental and control) had a total score of around 25 at baseline, which represents a low risk of falling. The experimental group did not show any significant changes after the exercise program while the control group did decrease this score down to 24, getting close to the category of moderate risk of falling. However, even though this decrease was statistically significant, the clinical relevance of a 1-point decrease in the Tinetti total score needs to be interpreted with caution.

Some limitations of the study should also be recognized. First, an important limitation was the sample size, which was rather small, and does not allow for generalization of the results. Another limitation is the lack of randomization between the experimental group and the control group. In regards to gait measurements, some frequent gait adaptations such as step and stride length and frequency were not measured in this study and should be considered in future research. The correlation of the fitness tests with cognitive tests after the intervention could be also of interest. Finally, a healthy control group to compare results would have been appropriate. 


\section{CONCLUSIONS}

A group-based exercise program focused mainly on different aerobic exercises represents a feasible strategy for improving physical fitness in people with Mild Cognitive Impairment. After the intervention, those who participated in the exercise program presented gains in the 6MWT, the TGUG, and the 8-meter walk test while the performance of the control group in these tests remained unchanged. This implies cardiovascular benefits, improved gait speed and enhanced dynamic balance. The quality of gait and the static balance showed no significant change in the experimental group, while decreased in the control group. The fact that there were no drop outs during the intervention is also a good marker of the feasibility of the program. Further research, including a larger sample, randomization, and a healthy control group, is needed to confirm the findings of this study.

\section{ACKNOWLEDGEMENTS}

We would like to acknowledge the Neurology Unit of the Hospital de San Vicente for their valuable contribution to this study.

\section{FUNDING}

The study was funded by the University of Alicante.

\section{REFERENCES}

1. ABBOTT RD, WHITE RR, ROSS GW, MASAKI KH, CURB JD, PETROVITCH H. Walking and Dementia in Physically Capable Elderly Men. The Journal of the American Medical Association. 2004; 292:1447-1453.

2. AMAND E, THOMAS DR. Supervised exercise to reduce agitation in severely cognitively impaired persons. Journal of the American Medical Directors Association. 2009; 10:271-276.

3. ARKIN SM. Student-led exercise sessions yield significant fitness gains for Alzheimer's patients. American Journal of Alzheimer's Disease and Other Dementias. 2003; 18(3):159-170.

4. BAKER LD, FRANK LL, FOSTER-SCHUBERT K, GREEN PS, WILKINSON CW, MCTIERNAN A, PLYMATE SR, FISHEL MA, WATSON GS, CHOLERTON BA, DUNCAN GE, MEHTA PD, CRAFT S. Effects of aerobic exercise on mild cognitive impairment: a controlled trial. Arch Neurol. 2010; 67:71-79.

5. BERMEJO P, MARTIN-ARAGON S, BENEDI J, SUSIN C, FELICI E, GIL P, RIBERA JM, VILLAR AM. Differences of peripheral inflammatory markers between mild cognitive impairment and Alzheimer's disease. Immunology Letters. 2008; 117:198-202.

6. BROOKMEYER R, JOHNSON E, ZIEGLER-GRAHAM K, ARRIGHI HM. Forecasting the global burden of Alzheimer's disease. Alzheimers Dementia. 2007; 3:186-191.

7. CHRISTOFOLETTI G, OLIANI MM, GOBBI S, STELLA F, GOBBI LTB, CANINEU PR. A controlled clinical trial on the effects of motor intervention on balance and cognition in institutionalized elderly patients with dementia. Clin Rehabil. 2008; 22:618-626.

8. ENRIGHT PL, MCBURNIE MA, BITTNER V, TRACY RP, MCNAMARA R, ARNOLD A, NEWMAN $A B$. The 6 minute walk test: a quick measure of functional status in elderly adults. Chest. 2003; 123(2):387-398.

9. ENRIGHT PL, SHERRILL DL. Reference equations for the six-minute walk in healthy adults. Am J Respir Crit Care Med. 1998; 158(5 Pt 1):1384-1387. 
10. GATES N, FIATARONE-SINGH MA, SACHDEV PS, VALENZUELA M. The Effect of Exercise Training on Cognitive Function in Older Adults with Mild Cognitive Impairment: A Meta-analysis of Randomized Controlled Trials. Am J Geriat Psychiat (in press). 2013.

11. GEDA YE, ROBERTS RO, KNOPMAN DS, CHRISTIANSON TJH, PANKRATS VS, IVNIK RJ. Physical Exercise, Aging, and Mild Cognitive Impairment. Arch Neurol. 2010; 67(1):80-86.

12. HAAN MN, WALLACE R. Can dementia be prevented? Brain aging in a population-based context. Annu Rev Public Health. 2004; 25:1-24.

13. KARP A, PAILLARD-BORG S, WANG HX, SILVERSTEIN M, WINBLAD B, FRATIGLIONI L. Mental, Physical and Social Components in Leisure Activities Equally Contribute to Decrease Dementia Risk. Dementia \& Geriatrics Cognitive Disorders. 2006; 21:65-7.

14. KEMOUN G, THIBAUD M, ROUMAGNE N, CARETTE P, ALBINET C, TOUSSAINT L, DUGUE B. Effects of a physical training programme on cognitive function and walking efficiency in elderly persons with dementia. Dementia \& Geriatric Cognitive Disorders. 2010; 29:109-114.

15. KÖPKE S, MEYER G. The Tinetti test. Z Gerontol Geriat. 2006; 39:288-291.

16. LAM LCW, CHAU RCM, WONG BML, FUNG AWT, LIU VWC, TAM CCW, CHAN WM.). Interim follow-up of a randomized controlled trial comparing Chinese style mind body (Tai Chi) and stretching exercises on cognitive function in subjects at risk of progressive cognitive decline. Int $J$ Geriatr Psych. 2011; 26:733-740.

17. LARSON EB, WANG L, BOWEN JD, MCCORMICK WC, TERI L, CRANE P, KUKULL W. Exercise Is Associated with Reduced Risk for Incident Dementia among Persons 65 Years of Age and Older. Ann Intern Med. 2006; 144:73-81.

18. LAURIN D, VERREAULT R, LINDSAY J, MACPHERSON K, ROCKWOOD K. Physical activity and risk of cognitive impairment and dementia in elderly persons. Arch Neurol. 2001; 58(3):498-504.

19. LAUTENSCHLAGER NT, KOX KL, FLICKER L, FOSTER JK, VAN BOCKXMEER FM, XIAO J, ALMEIDA OP. Effect of physical activity on cognitive function in older adults at risk for Alzheimer's disease: a randomized controlled trial. The Journal of the American Medical Association. 2008; 300(9):1027-1037.

20. MCGOUGH EL, KELLY VE, LOGSDON RG, MCCURRY SM, COCHRANE BB, ENGEL JM, TERI L. Associations Between Physical Performance and Executive Function in Older Adults With Mild Cognitive Impairment: Gait Speed and the Timed "Up \& Go" Test. Phys Ther. 2011; 91:1198-1207.

21. MENZ HB, LORD SR, FITZPATRICK RC. Age-related differences in walking stability. Age and Ageing. 2003; 32:137-142.

22. PETERSEN RC. Mild cognitive impairment as a diagnostic entity. J Intern Med. 2004; 256(3):183194.

23. PETERSEN RC, SMITH GE, WARING SC, IVNIK RJ, TANGALOS EG, KOKMEN E. Mild cognitive impairment: clinical characterization and outcome. Arch Neurol. 1999; 56:303-08.

24. PODEWILS LJ, GUALLAR E, KULLER LH, FRIED LP, LOPEZ OL, CARLSON M, LYKETSOS CG. Physical activity, APOE genotype, and dementia risk: Findings from the cardiovascular health cognition study. Am J Epidemiol. 2005; 161: 639-651.

25. RIMMER JH, SMITH D. Alzheimer's disease. In Durstine JL, Moore GE, Painter PL, Roberts SD (Eds.). ACSM's management for persons with chronic diseases and disabilities. Human Kinetics. Champaign, Illinois, 2009:368-374.

26. ROVIO S, KÅREHOLT I, HELKALA EL, VIITANEN M, WINBLAD B, TUOMILEHTO J, KIVIPELTO M. Leisure-time physical activity at midlife and the risk of dementia and Alzheimer's disease. Lancet Neurolology. 2005; 4(11):690-1. DOI:10.1016/S1474-4422(05)70198-8.

27. RUBENSTEIN LZ. Instrumentos de evaluación. In: Abrams WB, Berkow R. El Manual Merck de Geriatría. Barcelona: Ed Doyma,1992:1251-1263. 
28. SCHERDER E, EGGERMONT L, SWAAB D, VAN HEUVELEN M, KAMSMA Y, DE GREEF M, VAN WIJCK R, MULDER T. Gait in ageing and associated dementias; its relationship with cognition. Neurosci Biobehav R. 2007; 31:485-497.

29. SHERIDAN PL, HAUSDORFF JM. The Role of Higher-Level Cognitive Function in Gait: Executive Dysfunction Contributes to Fall Risk in Alzheimer's Disease. Dement Geriatr Cogn Disord. 2007; 24:125-137.

30. SHUMWAY-COOK A, BRAUER S, WOOLLACOTT M. Predicting the probability for falls in community-dwelling older adults using the Timed Up \& Go Test. Phys Ther. 2000; 80:896-903.

31. SIMONS LA, SIMONS J, MCCALLUM J, FRIEDLANDER Y. Lifestyle factors and risk of dementia: Dubbo Study of the elderly. Med J Australia. 2006; 184:68-70. Retrieved from www.mja.com.au.

32. STEFFEN TM, HACKER T, MOLLINGER L. Age- and Gender-Related Test Performance in Community-Dwelling Elderly People: Six-Minute Walk Test, Berg Balance Scale, Timed Up \& Go Test, and Gait Speeds. Phys Ther. 2002; 82(2):128-137.

33. TAAFFE DR, IRIE F, MASAKI KH, ABBOT R, PETROVITCH H, ROSS W, WHITE LR. Physical activity, physical function, and incident dementia in elderly men: The honolulu-asia aging study. The Journals of Gerontology Series A. 2008; 63(5):529-535. Retrieved from http://biomedgerontology.oxfordjournals.org/.

34. TAPPEN RM, ROACH KE, APPLEGATE EB, STOWELL P. Effect of a combined walking and conversation intervention on functional mobility of nursing home residents with Alzheimer disease. Alzheimer Dis Assoc Disord. 2000; 14:196-201. Retrieved from www.ncbi.nlm.nih.gov/pmc/articles.

35. TAYLOR AH, CABLE NT, FAULKNER G, HILLSDON M, NARICI M, VAN DER BIJ AK. Physical activity and older adults: A review of health benefits and the effectiveness of interventions. J Sport Sci. 2004; 22(8):703-725.

36. TINETTI ME, BAKER DI, MCAVAY G, CLAUS EB, GARRETT P, GOTTSCHALK M, KOCH ML, TRAINOR K, HORWITZ RI. A multifactorial intervention to reduce the risk of falling among elderly people living in the community. N Engl J Med. 1994; 331:821-827.

37. TINETTI ME, WILLIAMS TF, MAYEWSKI R. Fall Risk Index for elderly patients based on number of chronic disabilities. Am J Med. 1986; 80:429-434.

38. TROOSTERS T, GOSSELINK R, DECRAMER M. Six minute walking distance in healthy elderly subjects. Eur Respir J. 1999; 14:270 274 .

39. UEMURA K, TAKEHIKO D, SHIMADA H, MAKIZAKO H, YOSHIDA D, TSUTSUMIMOTO K, ANAN Y, SUZUKI T. Effects of Exercise Intervention on Vascular Risk Factors in Older Adults with Mild Cognitive Impairment: A Randomized Controlled Trial. Dement Geriatr Cogn Disord Extra. 2012; 2:445-455.

40. WILLIAMS CL, TAPPEN RM. Effect of exercise on mood in nursing home residents with Alzheimer's disease. American Journal of Alzheimer's Disease and Other Dementias. 2007; 22: 389-397.

41. YAGÜEZ L, SHAW K, MORRIS R, MATTHEWS D. The effects on cognitive functions of a movement-based intervention in patients with Alzheimer's type dementia: a pilot study, International. J Geriatr Psychiat. 2011; 26:173-181. 